\title{
O Relativismo Cognitivo é AutorRefutante? ${ }^{1}$
}

Robinson Guitarrari ${ }^{2}$

RESUMO: Hilary Putnam procurou solapar o relativismo cognitivo, mediante acusaçóes de incoerência autodestrutiva. A concepçáo de Thomas Kuhn de desenvolvimento do conhecimento científico ocupa um lugar de destaque nesse empreendimento crítico, e a incomensurabilidade entre paradigmas rivais constitui o núcleo da disputa. Putnam afirmou que a incomensurabilidade é autorrefutante, levando em conta apenas sua dimensão semântica. Este artigo examina essa investida antirrelativista. Considero dois sentidos de autorrefutaçáo, o material e o formal, e defendo que essa acusação não atinge a referida formulação semântica. Adicionalmente, mostro que a dimensão epistemológica da incomensurabilidade também não é afetada.

PALAVRAS-CHAVE: Relativismo epistemológico. Relativismo cognitivo. Incomensurabilidade. Autorrefutação. Putnam. Kuhn.

O relativismo cognitivo é autorrefutante. ${ }^{3}$ Putnam (1981, p. 113119) defendeu essa tese com certo detalhe, em Reason, truth and history, e de maneira breve, em Realism with a human face (PUTNAM, 1990, p. 22-23). Como se notará, do modo como foi apresentada, ela guarda uma vagueza a ser examinada. Daí a necessidade de fixar os termos: o que se entende por autorrefutante e o que se entende por relativismo cognitivo.

Há duas acepçôes de "autorrefutação" destacadas por Putnam. Chamarei uma de formal e a outra de material. Na primeira acepção, "[u]ma 'suposição autorrefutante’ é aquela cuja verdade implica a sua falsidade.” (PUTNAM,

\footnotetext{
${ }^{1}$ http://dx.doi.org/10.1590/S0101-31732016000100008

${ }^{2}$ Professor Adjunto do Departamento de Filosofia/ICHS da UFRRJ. E-mail: robinsonguitarrari@ gmail.com

${ }^{3}$ Essa é uma dentre várias acusaçóes de incoerência autodestrutiva que Putnam aponta, no relativismo cognitivo. Convém ressaltar que, desde as suas primeiras defesas do realismo interno, cinco objeçóes apresentadas no domínio de uma epistemologia geral contra o relativismo cognitivo podem ser claramente identificadas: (i) a autorrefutação (1981, p. 113-119; 1990, p. 22-23); (ii) o igualitarismo epistemológico (1981, p. 119-120); (iii) o regresso infinito (1981, p. 120-121); (iv) o caso de o relativismo ser absolutamente verdadeiro (1981, p.121); (v) a ausência de padrōes objetivos de avaliação (1981, p. 122). Neste artigo, examino a pertinência da acusação (i).
} 
1981, p. 7). Isso ocorre com o enunciado Todos os enunciados gerais são falsos. $\mathrm{Na}$ outra, "[...] uma tese é chamada 'autorrefutante', se a suposição de que a tese é cogitada ou enunciada implica sua falsidade.” (PUTNAM, 1981, p. 7-8). É o caso de Eu não existo. A diferença entre ambas parece residir no fato de que a forma do enunciado Todos os enunciados gerais são falsos é suficiente para que se retire a contradição, enquanto a autorrefutação de Eu não existo depende também da referência dos termos no ato enunciativo.

A expressão "relativismo cognitivo" reúne uma família de concepções sobre o conhecimento que é marcada pela defesa da tese de que a compreensão ou a justificação ou a verdade acerca de uma unidade de conhecimento é relativa a algum referencial. Isso encapsula duas teses. Uma delas é que essas concepçóes afirmam a existência de padrôes para avaliar uma unidade de conhecimento. A outra declara a inexistência de padróes absolutos, universais, neutros ou imparciais para avaliar essas unidades de conhecimento. ${ }^{4}$

Putnam entende que qualquer exemplar de relativismo cognitivo é autorrefutante. Contudo, ele a articula contra o registro semântico da incomensurabilidade entre paradigmas rivais, tal como apresentada e defendida por Kuhn. Procura-se mostrar que o tipo de relativismo cognitivo que a concepção kuhniana de desenvolvimento científico envolve não é autorrefutante. Para evidenciar esse ponto, serão expostas duas linhas argumentativas independentes: uma trata da incomensurabilidade semântica e outra considera a incomensurabilidade epistemológica. ${ }^{5}$ Tanto em um caso como em outro, o relativismo cognitivo se apresenta. A incomensurabilidade entre paradigmas rivais instaura um relativismo cognitivo, tendo em vista que ela nega a existência de padróes cognitivos neutros para a avaliação do paradigma,

\footnotetext{
${ }^{4}$ Essas duas características do relativismo cognitivo podem ser notadas em diversas interpretaçóes do lema protagórico O homem é a medida de todas as coisas (cf. BURNYEAT, 1976a, 1976b). Elas também foram admitidas mais recentemente por Rorty (1985, p. 23-24). Embora seja difícil encontrar um filósofo que se declare relativista, tendo em vista suas variedades e associaçôes apressadas dessas variedades com o irracionalismo, tal como foram feitas por Popper (LAKATOS; MUSGRAVE, 1970, p. 56) e por Lakatos (LAKATOS; MUSGRAVE, 1970, p. 93), ao tratarem da concepção kuhniana de desenvolvimento científico, é possível notar em Kuhn certa forma de relativismo cognitivo em sua concepção de racionalidade científica (GUITARRARI, 2004). Putnam também considera, em seu ataque, as posiçốes relativistas de Feyerabend e de Foucault (PUTNAM, 1981, p. 113-114). Antecipando o que se frisará, a afirmação de que toda posição (teoria, paradigma etc.) é tão boa quanto qualquer outra não é uma forma de relativismo cognitivo, pois supóe, nesse pronunciamento igualitarista, uma medida comum.

${ }^{5} \mathrm{O}$ artigo "Kuhn e as dimensōes da incomensurabilidade" (GUITARRARI; PLASTINO, 2014) traz a importância de se distinguir os registros semântico e epistemológico dessa tese central do quadro kuhniano de desenvolvimento científico.
} 
mas mantém (por ser entre paradigmas a incomensurabilidade) a existência de padróes de avaliação. No registro semântico, a incomensurabilidade instala um relativismo quanto à noção de compreensão. No âmbito epistemológico, ela implica um relativismo quanto à noção de justificação. A ideia é que nenhuma dessas dimensões da incomensurabilidade implica autorrefutação. Isso vale tanto para a acepção formal como para a material de tal acusação.

Para tanto, levarei em conta, principalmente, pronunciamentos de Kuhn, em The structure of scientific revolutions (1970) e em The essential tension (1977), sobre a incomensurabilidade epistemológica, e o desenvolvimento de suas ideias sobre a incomensurabilidade semântica, em artigos posteriores a esse período ${ }^{6}$. A ideia é que essa acusação não atinge a posição kuhniana e que, portanto, não possui o alcance que Putnam lhe atribui.

\section{RELATIVISMO E AUTORREFUTAÇÃo}

Em Reason, truth andhistory, Putnam examinao que considerasero núcleo do problema de uma das concepçóes relativistas acerca do desenvolvimento da ciência mais bem formuladas: a tese da incomensurabilidade, defendida tanto por Kuhn como por Feyerabend. Para Putnam (1981, p. 114), “[...] essa tese [...] é autorrefutante.”. Sua crítica incide em uma dimensão semântica: “[...] os termos usados em outra cultura, por exemplo, o termo "temperatura" como usado pelos cientistas do século XVII, náo podem ser igualados em significado ou em referência com quaisquer termos ou expressóes que nós possuamos." (PUTNAM, 1981, p. 114).

Sem ter como equacionar as referências ou os significados de um termo usado em paradigmas rivais, Putnam nota a impossibilidade de tradução dos usos de um mesmo termo, quando se considera a incomensurabilidade semântica. Com base nisso, ele mantém que

[...] se esta tese fosse realmente verdadeira, então não poderíamos traduzir outras linguagens de forma alguma - ou mesmo estágios passados de nossa

\footnotetext{
${ }^{6}$ Essa particular acusação de incoerência foi colocada por Putnam contra as formas de relativismo cognitivo, numa época em que defendeu o realismo interno. Mas ela continuou a ser usada tanto no período de transiçâo, em que passa a questionar pressupostos do realismo interno, como na sua fase atual, em que Putnam defende uma forma de realismo natural (também chamado de direto ou do senso comum). Isso aparece, por exemplo, em Renewing philosophy (1992, p. 7, 71-72), em Pragmatism (1995, p. 75) e em The collapse of the fact/value dichotomy and other essays (2002, p. 142-143). O exame da acusação de autorrefutação que se propóe aqui constitui uma avaliação do trabalho crítico de Putnam, tendo em vista as reais limitaçóes e dificuldades associadas a formas de relativismo cognitivo.
} 
própria linguagem. Se não podemos, de forma alguma, interpretar ruídos de organismos, entấo náo temos base para considerá-los seres pensantes, falantes ou mesmo pessoas. (PUTNAM, 1981, p. 114).

Putnam entende que a possibilidade de tradução é condição necessária para caracterizar um indivíduo como um ser que fala e pensa. Por não cumprir essa exigência, o relativismo apoiado na tese da incomensurabilidade assumiria, em sua formulação semântica, a falência de nossa capacidade cognitiva.

Todavia, em que sentido o relativismo resultante da incomensurabilidade semântica seria autorrefutante? Trata-se de uma autorrefutação formal ou material? De fato, esse não é um ponto claro, nos textos em que Putnam tratou do tema, muito embora haja evidências de que a autorrefutação seja material, como veremos em seguida. Por isso, serão analisados os dois casos.

Nas duas seções subsequentes, a acusação de autorrefutação é tomada de acordo com sua acepção material. Em primeiro lugar, procura-se mostrar que ela não se aplica à incomensurabilidade semântica. Em seguida, argumenta-se em favor de que a autorrefutação material também não atinge o relativismo cognitivo decorrente da incomensurabilidade epistemológica (tese segundo a qual há diferenças irredutíveis entre problemas considerados relevantes, entre os padróes de explicação e entre os valores cognitivos utilizados por defensores de paradigmas rivais). Depois disso, examina-se a acusação de que o relativismo kuhniano é autorrefutante de um ponto de vista formal. A ideia é ressaltar que há formas de relativismo cognitivo (sobre a compreensão da linguagem e sobre a justificação de escolha de paradigmas) que não são autorrefutantes.

\section{INCOMENSURABILIDADE SEMÂNTICA E AUTORREFUTAÇĀO MATERIAL}

De acordo com a acepção material de "autorrefutante", para que a suposição de verdade da incomensurabilidade semântica implique sua falsidade, é necessária sua enunciação. De fato, há algum respaldo para essa interpretação, em Realism with a human face:

[...] o relativismo, assim como o realismo, assume que se pode estar, ao mesmo tempo, dentro e fora de uma linguagem. No caso do realismo, isso não é uma contradição imediata, [...] pois todo o conteúdo do realismo subjaz na afirmação de que faz sentido pensar em um ponto de vista do olho de Deus (ou melhor, de uma "visão a partir de lugar algum"); mas, no caso do relativismo, isso constitui uma autorrefutação. (PUTNAM, 1990, p. 23). 
Putnam não explicita a cadeia argumentativa da qual decorreria a autocontradição do relativismo. $\mathrm{O}$ esquema de argumento indica que se trata de uma versão semântica, uma vez que a autorrefutação se seguiria por conta de o relativista estar, ao mesmo tempo, dentro e fora da linguagem.

A partir disso, é possível entender que a mencionada incoerência se seguiria do seguinte raciocínio: o relativista não poderia proferir que há uma incomensurabilidade semântica entre paradigmas rivais, porque a expressão da incomensurabilidade semântica envolveria uma espécie de tradução entre termos centrais de paradigmas rivais que ela própria nega. Em outras palavras, a tradução seria exigida para declarar a impossibilidade de tradução.

Para Putnam, a defesa da incomensurabilidade envolve uma confusão entre "conceito" e "concepção". Embora reconheça a dificuldade de estabelecer essa distinção, mantém que toda interpretação a pressupõe (PUTNAM, 1981, p. 116) e que, na prática da traduçáo, um termo $a$ é traduzido, à medida que as referências do velho e do novo termo se equivalem. Assim, o conceito de $a$ equivale ao conceito de $b$, quando as referências de ambos se equivalem. Já uma concepção de $a$ é um conjunto de crenças sobre $a$.

Com base nessa distinção, Putnam procura evidenciar a tese de que duas concepções distintas não impossibilitam a tradução de uma na outra; ao contrário, "[...] não podemos dizer que concepçôes diferem e como elas diferem se não pudermos traduzir” (PUTNAM, 1981, p. 117). E prossegue:

Quando traduzimos uma palavra, como, por exemplo, temperatura, igualamos a referência e, à medida que sustentamos a nossa traduçáo, o sentido da expressão traduzida com [a referência e o sentido de] nosso próprio termo "temperatura", ao menos quando usamos nesse contexto. [...] Neste sentido, igualamos o "conceito" em questão com o nosso próprio "conceito" de temperatura. Mas proceder assim é compatível com o fato de que os cientistas do século dezessete, ou quaisquer outros, podem ter tido uma concepçâo diferente de temperatura, ou seja, um conjunto de crenças sobre ela e sobre sua natureza diferente daquele que temos, diferentes "imagens de conhecimento", e também diferentes crenças últimas acerca de muitos outros assuntos. (PUTNAM, 1981, p. 117).

$\mathrm{O}$ fato de as concepções diferirem não é suficiente para estabelecer a impossibilidade de tradução de uma linguagem em outra. Ele enfatiza que "[...] a comparação pressupóe que haja algumas comensurabilidades.” (PUTNAM, 1981, p. 118). 
Putnam não concede que a tradução seja o produto das interpretaçóes que nos ajudam a entender concepçóes diferentes das nossas. Ele defende a ideia de que os significados e as referências das expressóes de culturas distintas podem ser igualados (PUTNAM, 1981, p. 117).

Por sua vez, o relativismo kuhniano impediria que conceitos de outra linguagem pudessem ser inteligíveis para nós. Isso ocorreria porque o relativista, comprometido com a incomensurabilidade semântica e, portanto, com a intraduzibilidade, entenderia que as referências e os significados dos termos de linguagens de paradigmas rivais náo poderiam ser igualados.

Para ficar livre da autorrefutação que nos conduziria à impossibilidade de nos considerarmos "[...] seres pensantes, falantes ou mesmo pessoas" (PUTNAM, 1981, p. 114) Putnam assume a existência de critérios de semelhança de referência e sentido como condição de possibilidade de compreensão de outras linguagens. Dizer que um esquema de tradução bem-sucedido não captura realmente o sentido ou a referência do original é "[...] uma ilusão de sentido" (PUTNAM, 1981, p. 116). Em oposição ao relativismo semântico, ele afirma:

Uma vez admitido que podemos encontrar um esquema de traduçáo que "funcione" no caso de um texto do século dezessete, pelo menos no contexto fixado pelos nossos interesses e pelo uso ao qual a tradução possa servir, que sentido tem em dizer que, nesse contexto, a traduçáo não captura "realmente" o sentido ou a referência do original? [...] Pode-se entender a asserçáo de acordo com a qual uma tradução falha, ao tentar capturar exatamente o sentido ou a referência do original, como uma admissão de que um esquema de traduçáo melhor poderia ser encontrado. (PUTNAM, 1981, p. 116).

O fato de não haver critérios de semelhança de sentido ou de referência, independentes da linguagem culturalmente impregnada, não inviabiliza juízos acerca de melhores traduçóes.

Putnam está certo, ao considerar que a incomensurabilidade semântica nega a possibilidade de tradução. Mas se equivoca, tanto em relação ao tipo de tradução ao qual Kuhn se refere como quanto às suas implicaçôes.

Em "Commensurability, comparability, communicability" (KUHN, 2000a), a incomensurabilidade semântica diz respeito à impossibilidade de produzir uma tradução sem perdas de significado e referência entre teorias rivais. Nesse contexto, "tradução" se refere à atividade que pressupóe o conhecimento das linguagens envolvidas no processo e também que sempre existe um termo ou sequência de termos da linguagem estrangeira que captura a referência do termo utilizado na linguagem original. Nesse sentido, é 
impossível uma tradução sem perdas entre linguagens de paradigmas rivais (KUHN, 2000a, p. 34, 36).

Contudo, isso não quer dizer que uma linguagem estrangeira não possa ser interpretada de tal modo que o resultado dessa atividade demonstre seu êxito. A atividade de interpretar náo exige o domínio prévio da linguagem estrangeira e é suficiente para que se compreenda uma posição rival e para que a comunicação se estabeleça.

Como frisa Kuhn, a noção de incomensurabilidade é "[...] bem mais modesta do que meus críticos supóem.” (KUHN, 2000a, p. 36). Ela não é total, em nenhuma de suas dimensôes. Ela é local e permite a interpretação de uma linguagem estrangeira (KUHN, 2000a, p. 36).

Essa versão branda da incomensurabilidade semântica foi apresentada cerca de duas décadas depois de suas primeiras formulações, na primeira edição de The structure of scientific revolutions. ${ }^{7}$ Seus esclarecimentos, sobretudo, com a explicitação das implicaçôes dessa formulação para o debate interparadigmático, em grande parte, resultaram de tentativas de explicitar seu posicionamento à luz de consideraçóes de seus críticos. Ela concede que a maioria dos termos comuns às duas teorias rivais tenha a sua referência e o seu significado preservados, embora sempre existam termos (em geral, interdefinidos) que não podem ser

\footnotetext{
${ }^{7} \mathrm{Na}$ edição de 1962 de The structure of scientific revolutions, Kuhn afirma que "[u]ma mudança na rede de compromissos de uma disciplina altera a rede conceitual pela qual os cientistas veem o mundo" (1970, p. 102). No "Postscript", em 1969, declara que defensores de paradigmas rivais "[...] não podem recorrer a uma linguagem neutra, que seja utilizada da mesma maneira e que seja adequada para o enunciado de ambas as teorias ou mesmo das consequências empíricas dessas teorias." (KUHN, 1970, p. 201). A referência à impossibilidade de acessar uma linguagem neutra também aparece em "Reflections on my critics" (originalmente publicado em 1970): "[a] comparação ponto a ponto de duas teorias sucessivas exige uma linguagem em que pelo menos as consequências empíricas de ambas possam ser traduzidas sem perdas ou mudanças. [...] Feyerabend e eu argumentamos detalhadamente que tal vocabulário não está disponível.” (KUHN, 2000d, p. 162). Em "Commensurability, comparability, communicability”, Kuhn às vezes não faz referência à linguagem neutra: "[...] se duas teorias são incomensuráveis, elas devem ser afirmadas em linguagens mutuamente intraduzíveis" (KUHN, 2000a, p. 34). Essa característica é notada por Hoyningen-Huene, em comentário segundo o qual, nesse artigo, a intraduzibilidade envolve diretamente a incomensurabilidade (HOYNINGENHUENE, 1993, p. 215). Mas, ainda no artigo "Commensurability, comparability, communicability", Kuhn afirma que a incomensurabilidade semântica implica que "[...] não existe linguagem neutra, ou outra qualquer, em que ambas as teorias, concebidas como conjuntos de sentenças, podem ser traduzidas sem resíduos ou perdas." (KUHN, 2000a, p. 36). É possível entender que, nesse artigo, a incomensurabilidade semântica implica que "[...] duas linguagens rivais não podem ser traduzidas sem perdas de significado ou referência, seja porque se nega a existência de uma linguagem neutra, seja porque as duas linguagens disponíveis na disputa são tais que essa tradução traria perdas." (GUITARRARI; PLASTINO, 2014, p. 36).
} 
traduzidos sem perdas (KUHN, 2000a, p. 36). Isso torna possível a existência de esquemas interpretativos bem-sucedidos.

$\mathrm{Na}$ atividade de interpretação, os termos que possuem suas propriedades semânticas inalteradas são fundamentais para que os termos que não podem ser traduzidos sejam compreendidos. Permite-se inclusive que as vantagens e desvantagens das linguagens sejam comparadas. Segundo Kuhn, a parte comensurável é suficiente para defensores de paradigmas rivais explorarem os significados dos termos incomensuráveis, compreenderem-se, comunicaremse e estabelecerem comparaçóes (KUHN, 2000a, p. 36).

Intraduzibilidade sem perdas não implica impossibilidade de compreensão, incomunicabilidade ou incomparabilidade (KUHN, 2000a, p. 44). Com a incomensurabilidade semântica, os membros de uma comunidade científica não estão impedidos de compreender um paradigma rival, nem de se comunicar com seu opositor, apresentando seu modo de ver as suas diferenças e estabelecendo as suas preferências sobre quais são os problemas científicos relevantes e como resolvê-los. ${ }^{8}$

Putnam entende que o uso de critérios de semelhança de referências e significados das expressóes de paradigmas rivais é condição necessária para uma tradução bem-sucedida. Desse modo, sem igualar a referência de termos, não é possível compreender uma linguagem estrangeira. A compreensão envolve a possibilidade de tradução e, por conta disso, a possibilidade de estabelecer a equivalência das referências dos termos de teorias rivais. Assim, para Putnam, a defesa de uma incomensurabilidade local não resolveria o problema de explicar por que as nossas interpretaçôes são tão bem-sucedidas.

Entretanto, a compreensão de uma nova linguagem não requer a existência de uma tradução para a linguagem nativa: "[a] habilidade de aprender uma linguagem [...] não garante a habilidade de traduzir de dentro e de fora dela” (KUHN, 2000b, p. 92). A impossibilidade de traduzir termo a termo uma linguagem estrangeira na linguagem nativa não implica a impossibilidade de aprendê-la. Com efeito, Kuhn (2000a, p. 39) assevera:

\footnotetext{
${ }^{8}$ Ao declarar, em "Commensurability, comparability, communicability", que "[...] somente para um pequeno subgrupo de termos (normalmente) interdefinidos e para as sentenças que os contêm os problemas de tradução realmente emergem" (KUHN, 2000a, p. 36), Kuhn descarta a interpretação de um holismo mais radical, indicadas em passagens de The structure of scientific revolutions, nas quais afirma que os paradigmas rivais "[...] raramente empregam, de uma maneira totalmente tradicional, esses elementos emprestados" e que "[...] termos, conceitos e experiências antigas estabelecem, dentro do novo paradigma, novas relaçôes entre si.” (KUHN, 1970, p. 149).
} 
Para interpretar a locução "Gavagai”, o antropólogo concebido por Quine não precisava descender de uma comunidade linguística que conhecesse coelhos e que possuísse uma palavra que refere a ele. [...] O antropólogo ou intérprete pode e, de fato, frequentemente aprende a reconhecer as criaturas evocadas pelo "Gavagai" dos nativos. Em vez de traduzir, o intérprete pode simplesmente conhecer o animal e o uso do termo nativo para ele.

Enquanto a tradução pressupõe que o tradutor conheça duas línguas, a interpretação não possui essa exigência.

De acordo com Kuhn, a aprendizagem da linguagem científica é, em certo aspecto, análoga à da linguagem ordinária. Nos dois processos, as indicaçóes de como os termos se aplicam à natureza são feitas com recurso à ostensão. Também se aprende a perceber e a discriminar unidades e padróes de semelhança. As percepçóes desses padróes de semelhança são lógica e psicologicamente anteriores a qualquer regra ou critério que se possa especificar. Por relaçóes de similaridade, igualmente em ambos os processos de aprendizagem, desenvolvemse as habilidades de perceber semelhanças e diferenças entre situaçóes complexas desconhecidas e outras conhecidas. Influenciado pelo segundo Wittgenstein, Kuhn entende que uma noção é apreendida pelo reconhecimento de uma complexa rede de semelhanças. Essas semelhanças qualificam os referentes da noção como membros de uma mesma família.

Um exemplo é apresentado em "Second thoughts on paradigms" (KUHN, 1977a). Assim como uma criança aprende a agrupar cisnes, gansos e patos, um iniciante em ciência aprende a perceber relaçóes de similaridade e não similaridade que são amplamente compartilhadas pela comunidade. Assim como uma criança adquire padróes de reconhecimento, independentes de qualquer enunciado geral ou critério definidor, um estudante imbui-se dos padróes linguísticos de reconhecimento, fornecidos pelos exemplares do paradigma aceito (KUHN, 1977a, p. 312-313).

Em suma, a incomensurabilidade semântica não implica a impossibilidade de comunicação nem deaprendizagem. ${ }^{9}$ A incomensurabilidade não é total, mas local. Com isso, embora não haja linguagem neutra, para que as referências e os sentidos das expressóes de linguagens rivais sejam tomados como equivalentes, a existência de comensurabilidades (para que faça

\footnotetext{
${ }^{9}$ Feyerabend (1987) possui essa mesma compreensão do processo de aprendizagem de uma linguagem e, contra Putnam, ressalta esse aspecto de maneira enfática: "Podemos aprender uma linguagem ou uma cultura a partir da estaca zero, como uma criança a aprende, sem desviar de nosso idioma nativo [...]. E podemos mudar nosso idioma nativo de modo que se torne capaz de expressar noçóes estrangeiras [...]." (FEYERABEND, 1987, p. 76).
} 
sentido apresentar diferenças entre paradigmas rivais), exigida por Putnam, é satisfeita dentro do quadro kuhniano do desenvolvimento científico. Nessas condiçôes de incomensurabilidade local, a possibilidade de aprendizagem de outra linguagem se abre, permitindo que membros de comunidades científicas rivais se compreendam, comuniquem-se e efetuem comparaçóes sobre os méritos cognitivos e pragmáticos dos paradigmas em jogo. Com isso, podese notar por que a tese da incomensurabilidade semântica não envolve uma contradição, quando enunciada: negar a possibilidade de tradução completa entre duas linguagens não exige a tradução entre elas; exige a compreensão de ambas, que pode ser obtida pelo processo de aprendizagem.

\section{INCOMENSURABILIDADE EPISTEMOLÓGICA E AUTORREFUTAÇÃO MATERIAL}

Outra linha argumentativa contra a acusação de que o relativismo kuhniano é materialmente autorrefutante é destacada com a dimensão epistemológica da incomensurabilidade kuhniana (KUHN, 1970, p. 103, 185-186). Ela gera uma forma de relativismo quanto à justificação da adesão a um paradigma, num período de ciência extraordinária, no qual a comunidade científica se divide em torno de paradigmas rivais. Esse aspecto foi desconsiderado por Putnam (1981, 1990), embora anteriormente sublinhado por Doppelt (1978), com base nos escritos de Kuhn. É possível notar que esse registro da incomensurabilidade e o relativismo cognitivo que dele decorre não são autorrefutantes, em sua acepção material.

A dimensão epistemológica afirma que paradigmas rivais possuem conjuntos distintos de problemas, valores e padrôes de solução de problemas, e que não existe um registro supraparadigmático neutro, imparcial, explícito, não ambíguo e decidível que resolva esse conflito. ${ }^{10}$ (Como se observa, essa formulação satisfaz os requisitos para uma definição de relativismo cognitivo.) Ela se apoia em casos da história das ciências maduras, uma história que revela perdas de explicação e mudanças de valores e de padrôes de avaliação.

Numa situação de escolha, um tipo de pesquisa conservadora, dogmática e cumulativa, o qual soluciona problemas, dirigido por um paradigma, confronta-se com um tratamento rival, que tem outros problemas, outras

\footnotetext{
${ }^{10}$ A incomensurabilidade epistemológica foi destacada por Doppelt, em "Kuhn's epistemological relativism: an interpretation and defense" (1978), contra críticas de irracionalidade baseadas na incomensurabilidade semântica para descartar a concepção de desenvolvimento da ciência proposta por Kuhn.
} 
maneiras de solucionar seus problemas, utilizando seus valores cognitivos e pragmáticos, dentre os quais seus padróes de avaliação explicativa.

As decisões científicas são tomadas com base em boas razões. Essa leitura do desenvolvimento das ciências maduras considera, sobretudo, as razóes que influenciam o grupo de cientistas, em vez das motivaçốes do cientista individual (KUHN, 1970, p. 153, 2000d, p. 131). Os mais respeitados defensores de paradigmas rivais podem apresentar as melhores razóes (ou mais persuasivas), aquelas vinculadas à sua espantosa capacidade de solucionar os problemas considerados importantes. Mas como não há registro comum de padrôes, estratégias e problemas em que as comunidades científicas rivais possam se apoiar, as boas razôes não são imparciais, nem implicam a formação de consenso.

Segundo Kuhn, as boas razóes são boas exatamente para aqueles que já as aceitaram como tais. Ele defende que, para quem propóe uma mudança de paradigma, as boas razóes estáo entre as que ressaltam a resolução de problemas que conduziram o antigo paradigma à crise (KUHN, 1970, p. 153), a precisão na resolução de problemas (KUHN, 1970, p. 153-154), a solução de problemas insuspeitados (KUHN, 1970, p. 154), bem como sua simplicidade (KUHN, 1970, 155). Os que defendem a permanência do antigo paradigma "[...] podem legitimamente alegar que, mesmo na área em crise, ele [o novo paradigma] é pouco superior ao seu rival tradicional”, tendo em vista a reconhecida capacidade do antigo paradigma em solucionar problemas e superar dificuldades (KUHN, 1970, p. 156), as perdas de explicaçóes que frequentemente ocorrem nas mudanças de paradigma (KUHN, 1970, p. 157), a falta de critérios imparciais para comparar a força dos argumentos usados no debate (KUHN, 1970, p. 157).

Kuhn não exclui, com isso, que o interesse, o poder (político ou econômico) e a autoridade possam cumprir um papel significativo em ciência. Embora não sejam decisivas para o desfecho do resultado da escolha entre paradigmas rivais, por parte da comunidade científica, as motivaçóes mais subjetivas dos cientistas individuais contribuem para que os riscos sejam distribuídos, sobretudo, no início de um período de crise, cumprindo assim um papel de manter ativo o processo de desenvolvimento da ciência madura (KUHN, 2000d, p. 158, 1977b, p. 332). Contudo, como ele frisou em "The trouble with the historical philosophy of science" (KUHN, 2000c), sua posição está distante da tese extrema segundo a qual "o poder e o interesse é tudo o que existe”, proclamada pelo programa forte em sociologia do conhecimento. Uma dificuldade central com essa perspectiva, conforme Kuhn, é que, se a 
negociação que dirige a avaliação das mudanças de crenças é resolvida apenas com referência a peculiaridades da biografia pessoal do cientista, fica difícil entender "[...] como a natureza entra nessa negociação." (KUHN, 2000c, p. 110). Diferentemente dessa corrente, Kuhn procura apresentar, em sua concepçáo de ciência, o papel que a natureza cumpre nos debates entre comunidades científicas rivais.

Se as boas razões, ressaltadas por Kuhn, internalizam informações acerca da natureza, deve-se enfatizar que, em uma situação de debate entre comunidades científicas rivais, elas não satisfazem o requisito de serem apresentadas em uma linguagem neutra adequada aos relatos observacionais, exigido por Popper, em "Normal science and its dangers" (POPPER, 1970). ${ }^{11}$

Ademais, as boas razốes funcionam como valores, não como regras. Kuhn afirma isso em "Reflections on my critics":

O que estou negando, entâo, não é a existência de boas razôes nem que tais razóes sejam do tipo usualmente descrito. Entretanto, estou insistindo em que tais razóes constituem valores usados para se fazer escolhas, em vez de regras de escolha. (KUHN, 2000d, p. 157-158).

O que está em jogo não é a satisfação de uma regra, mas a maximização de um valor. Além disso, ao considerar que as escolhas da comunidade científica estão baseadas em valores, fica aberta a possibilidade de que esses valores possam ser aplicados de diversas maneiras. Kuhn (2000c, p. 157-158) continua:

Os cientistas que as compartilham podem, apesar disso, fazer escolhas diferentes na mesma situação concreta. Dois fatores estão profundamente envolvidos. Em primeiro lugar, embora sejam todos constitutivos de boas razóes, em muitas situaçóes concretas, valores diferentes ditam conclusóes diferentes, escolhas diferentes. Em tais casos de conflitos de valores (p. ex., uma teoria é mais simples, embora a outra seja mais precisa), os pesos relativos atribuídos a diferentes valores por indivíduos diferentes podem cumprir um papel decisivo na escolha individual. Mais importante ainda é que [...] eles [os cientistas] náo aplicam todos do mesmo modo. A simplicidade, o escopo, a fertilidade e mesmo a precisão podem ser julgadas de maneiras bem diferentes por diferentes pessoas [...].

\footnotetext{
${ }^{11}$ Nessa polêmica, Kuhn aceita o rótulo de relativista, porque não equipara as teorias com representaçóes da natureza, nâo coloca a verdade como um objetivo da ciência nem entende que seja possível medir o progresso científico em direção a ela (KUHN, 2000d, p. 157-158). Além de as linguagens rivais não possuírem tradução completa, a história da ciência mostra, conforme Kuhn, que há perdas de explicação e mudança de padrốes de explicação e de valores.
} 
Valores podem apresentar conflitos e comunidades científicas rivais podem atribuir pesos distintos a esses valores, como também podem compreendê-los de modo diferente.

Dentro desse cenário, o relativismo cognitivo se coloca. Parafraseando Doppelt (1978, p. 63), cada paradigma é o melhor em seus próprios termos e não há outros termos a que se possa recorrer.

O juízo de que o paradigma vigente é melhor que seu rival não é contraditório com o juízo de que o rival é melhor que o vigente. Eles resultam de avaliaçóes em que as boas razóes, tomadas em cada caso conjuntamente, não são as mesmas.

A incomensurabilidade epistemológica também não se refuta, ao ser enunciada. Sua declaração é uma descrição de uma leitura da história da ciência, a saber: há mudanças, no desenvolvimento da ciência, em que os diferentes conjuntos de problemas, padrôes de avaliações e valores - utilizados por cientistas para fazer suas escolhas de paradigmas em competição - são irredutíveis entre si ou em relação a um terceiro. Essa declaração não é autorrefutante, pois não pressupóe padrão cognitivo comum (imparcial e também decisivo) na descrição de (supostos) fatos históricos de que os conjuntos de padrôes, problemas e valores cognitivos são distintos e irredutíveis entre si (ou a um terceiro). Ela apenas procura descrever um estado de coisas, uma diversidade peculiar de compromissos científicos, e, ao fazer isso, ela não pressupóe algo que nega.

\section{RELATIVISMO E AUTORREFUTAÇÃO FORMAL}

Ainda que a autorrefutação, em sua acepção material, não atinja o relativismo quanto à compreensão (derivado da incomensurabilidade semântica defendida por Kuhn), nem o relativismo quanto à justificação (gerado pela defesa da incomensurabilidade epistemológica), falta examinar se o relativismo cognitivo é autorrefutante, em termos formais.

Há especialmente uma concepção entendida como relativista que, de fato, é autorrefutante. Mas é um erro considerá-la relativista. Trata-se da posição que afirma que Toda afirmação de conhecimento é verdadeira.

Defender que toda declaração é verdadeira simpliciter, obviamente, viola o princípio de não-contradiçâo. Tendo em vista que seu quantificador 
universal varre declaraçóes, a concepção em questáo implica a sua negação, isto é, que nem toda afirmação de conhecimento é verdadeira.

De fato, a concepção que implica um resultado contraditório como esse é inconsistente e, portanto, do ponto de vista da lógica clássica, dela tudo se seguiria. Com isso, seria instalado um vale $t^{1} d^{12}$ e, com razáo, ela deveria ser considerada autorrefutante.

Uma tentativa de responder a essa alegação de incoerência foi apresentada por Meiland com uma noção de verdade relativa. Segundo ele, "[...] o conceito de verdade relativa, como usado por alguns relativistas, parece ser um conceito de uma relação ternária entre os enunciados, o mundo e um terceiro termo que ou são pessoas ou visóes de mundo ou situações históricas ou culturais." (MEILAND, 1977, p. 571).

Nesse sentido, o relativista poderia dizer que “[...] um enunciado $e$ é verdadeiro do ponto de vista $v$ " significa algo como " $e$ corresponde aos fatos do ponto de vista de $v$ " (MEILAND, 1977, p. 571). Assim, de pontos de vistas distintos, os enunciados quaisquer $e$ e não-e não são contraditórios.

Todavia, não é necessário defender uma concepção de verdade relativa, tomada como uma relação ternária, para responder ao problema da autorrefutação formal colocado dentro dos parâmetros apresentados acima. Além disso, a estratégia de Meiland envolve a defesa de uma obscura relação de correspondência.

Para responder à acusação formal de autorrefutação, é suficiente notar que tal objeção não compreende a posição relativista. Em outras palavras, é um erro considerar que Toda afirmação de conhecimento é verdadeira possa ser a expressão de alguma forma de relativismo cognitivo. A razão é que essa afirmação exclui uma característica crucial da ideia do relativismo: a existência de referenciais.

\footnotetext{
${ }^{12}$ A razão pela qual isso ocorreria fica mais evidente, quando se considera a semântica da lógica clássica. Seja $\Gamma$ uma teoria e $\alpha$ uma sentença de uma linguagem formalmente bem construída. Por definição, a sentença $\alpha$ é consequência do conjunto de sentenças $\Gamma$ se e somente se não existe circunstância em que as sentenças do conjunto $\Gamma$ são verdadeiras e a sentença $\alpha$ seja falsa. Ora, como uma teoria é fechada pela relação de consequência e, como, no nosso caso, ela comporta uma contradição, isso implica que não existe circunstância em que todas as sentenças de $\Gamma$ sejam verdadeiras (porque tal teoria comporta contradição). Desse modo, não existe circunstância em que todas as sentenças de $\Gamma$ sejam verdadeiras e a sentença $\alpha$ seja falsa. Assim, $\alpha$, qualquer que ela seja, segue-se como consequência da teoria $\Gamma$. Quando isso ocorre, dentro da lógica clássica, diz-se que a teoria é trivial.
} 
O relativismo se coloca num domínio em que se supóe a existência de pelo menos dois referenciais. Dentro desse domínio, afirma-se que as avaliaçóes das afirmaçóes de conhecimento devem ser feitas com referência aos padróes fornecidos pelo referencial adotado.

Isso náo implica que todo referencial escapa da autorrefutação (ou de qualquer outra acusação de incoerência). Mas fica evidente que a concepção relativista acerca do conhecimento não é formalmente autorrefutante.

De uma legítima perspectiva relativista, os enunciados Toda afirmação de conhecimento é verdadeira (para Protágoras) e Nem toda afirmação de conhecimento é verdadeira (para Platão) não são contraditórios. Esse é o ponto em jogo. ${ }^{13}$

Adicionalmente, ressalto que, como se trata aqui de mostrar que a acusação de autorrefutação náo se aplica ao caso kuhniano, e uma vez que a noção de verdade náo cumpre um papel relevante dentro de uma concepçáo kuhniana do desenvolvimento científico, uma alternativa é entender que a concepçáo de verdade não possui uma natureza substancial e conceitual que exija uma teoria da verdade. ${ }^{14}$

Assim, considera-se uma noção descitacional de verdade, na qual vale o esquema de equivalência "A sentença 'p' é verdadeira se e somente se p". Assumindo a tese da incomensurabilidade epistemológica entre paradigmas rivais, é possível observar, por exemplo, que as respostas de Priestley e de Lavoisier à questão Por que os metais aumentam seu peso quando aquecidos? não refutam a concepção relativista presente na proposta de Kuhn. Dizer que o metal aquecido aumentou seu peso porque o flogisto (com seu peso negativo) presente no metal foi emitido ao ar (no caso de Priestley) ou que o aumento de peso foi causado pela oxidação do metal (no caso de Lavoisier) são respostas

\footnotetext{
${ }^{13}$ Outra questão é se certos referenciais podem ser sustentados com base em seus próprios padrôes, em particular, se a perspectiva a partir da qual se afirma que Toda afirmação de conhecimento é verdadeira (para Protágoras) é autorrefutante. $\mathrm{O}$ relativismo cognitivo defende a existência de padrôes de avaliação. Esses padrôes funcionam como restriçôes. Isso implica que nem toda declaração expressa conhecimento. No caso em questáo, a perspectiva seria insustentável, segundo os padrôes da lógica clássica, porque, neste caso, a violaçáo do princípio de nâo contradiçăo leva à trivialidade da perspectiva, implicando, com isso, que toda declaração é uma legítima afirmação de conhecimento.

${ }^{14}$ Em 1991, no artigo "The road since Structure", Thomas Kuhn declara seu compromisso com uma concepção deflacionista de verdade: "Disse anteriormente que devemos aprender a avançar sem algo que se assemelhe à teoria da verdade como correspondência. Mas algo similar a uma teoria da verdade como redundância é urgentemente necessário para substituí-la, algo que introduzirá leis básicas da lógica (especialmente a lei de não contradiçấo) e que tornará a adesão a tais leis uma precondição para a racionalidade das avaliaçōes" (KUHN, 2000b, p. 99).
} 
incomensuráveis, incompatíveis. Cada paradigma fornece seus próprios elementos para responder à questão. Dizer que a resposta é verdadeira, dentro de cada paradigma, é simplesmente afirmar a resposta. Todavia, o fato de as respostas serem conjuntamente incomensuráveis não implica a autorrefutação do quadro proposto por Kuhn.

O que vale para a noção de verdade também vale para a noção de justificação. Com a incomensurabilidade epistemológica, fica claro que a pergunta sobre qual paradigma adotar permite respostas divergentes e baseadas em boas razóes.

As boas razões apresentadas por comunidades científicas rivais não são as mesmas. Elas se vinculam, em muitos aspectos, ao paradigma defendido (KUHN, 1970, p. 94). Isso gera limitaçôes para um modelo de racionalidade científica, mas essas limitações não configuram uma autorrefutação formal.

A incomensurabilidade e o tipo de vínculo que a comunidade científica mantém com o paradigma que adota explicam o aspecto aparentemente circular das justificações apresentadas. Há padrōes de avaliação, os quais devem ser concebidos como valores. A precisão, a abrangência, o poder preditivo e explicativo, a fertilidade, a simplicidade e a consistência interna e externa não formam um conjunto único de valores universais, imparciais, neutros e decisivos. Eles podem apresentar conflitos (KUHN, 1977b, p.322). Alguns podem ser ambíguos em algumas de suas aplicaçóes, como ocorre com a simplicidade (KUHN, 1977b, p. 324). Além disso, podem revelar diferenças relevantes em relação aos pesos atribuídos a cada padrão de avaliação (KUHN, 2000d, p. 157-158).

Isso não significa que uma decisão seja táo boa quanto qualquer outra. Esse igualitarismo epistemológico pressupóe o que o relativismo nega: um patamar imparcial e neutro, em que a razáo equaciona e determina a igualdade dos pesos dos argumentos em favor de cada paradigma. Ademais, Kuhn, em "Reflections on my critics", declarou explicitamente que não adota essa concepção: "[u]ma teoria científica não é tão boa quanto qualquer outra para fazer o que os cientistas fazem." (KUHN, 2000d, p. 160).

O relativismo kuhniano com respeito à justificação permite a formulação de juízos de superioridade em favor de um paradigma. Esses juízos presentes nas defesas de paradigmas rivais são incomensuráveis. Isso não é contraditório com o que Kuhn propóe, nem mesmo com o relativismo cognitivo presente em seu modelo de desenvolvimento científico. 


\section{CONSIDERAÇÓES FINAIS}

Putnam utilizou acusaçôes de incoerência autodestrutiva para descartar posiçóes filosóficas que engendram alguma forma de relativismo cognitivo. Uma delas é a de autorrefutação. Ao relacioná-la à tese da incomensurabilidade, ele procura atingir Kuhn, Feyerabend e Rorty, dentre outros. Procurei mostrar que esse argumento não atinge a posição defendida por Kuhn e que, portanto, não possui a força e o alcance tencionados em sua elaboração.

O tratamento dado por Putnam leva em conta apenas a incomensurabilidade semântica. Considerando a autorrefutação em sua acepção material, argumentei que esse registro da incomensurabilidade não implica sua falsidade, contrariamente ao que ele afirma. $O$ fato de a incomensurabilidade não ser total, permitindo a comparação e comunicação entre membros de comunidades que defendem paradigmas rivais, deixa aberta a possibilidade de interpretação de uma nova linguagem, a partir da linguagem habitual. Com isso, a enunciação dessa tese não implica que seu defensor esteja, ao mesmo tempo, dentro e fora da linguagem.

Além disso, mostrei que a dimensão epistemológica da incomensurabilidade, por si só, é responsável por uma forma de relativismo cognitivo que também não se autorrefuta, numa acepção material. Isso reforça a tese de que o relativismo kuhniano não é abatido pela acusação de autorrefutaçáo, pois náo só aquele vinculado à tese semântica da incomensurabilidade escapa a tal acusaçáo, como também o relativismo cognitivo vinculado à incomensurabilidade epistemológica.

No caso da autorrefutação formal, nota-se que o relativismo kuhniano também não implica sua falsidade. Adicionalmente, destaquei os equívocos vinculados à atribuição de autorrefutação a pronunciamentos filosóficos que não são relativistas, por definição.

Dada a impertinência da acusação de autorrefutação, fica a questão de se outro argumento de incoerência autodestrutiva é capaz de descartar qualquer forma de relativismo cognitivo.

\section{$* * *$}

Agradeço ao Prof. Dr. Caetano Ernesto Plastino, pelos comentários e sugestóes. 
GUITARRARI, Robinson. Is cognitive relativism self-refuting? Trans/form/ação, Marília, v. 39, n. 1, p 139-158, Jan./Mar., 2016.

\begin{abstract}
Hilary Putnam sought to undermine cognitive relativism by charging it with selfdestructive incoherence. Thomas Kuhn's conception of the development of scientific knowledge occupies a prominent place in that critical endeavor, and the incommensurability between rival paradigms constitutes the core of the dispute. Putnam claimed that incommensurability is selfrefuting, taking into account only its semantic dimension. This article examines this anti-relativist attack. I consider two senses of self-refutation, the material and the formal, and argue that they do not affect the semantic formulation of incommensurability. Additionally, I show that the epistemological dimension of incommensurability is also unaffected.
\end{abstract}

KEYWORDS: Epistemological Relativism, Cognitive Relativism, Incommensurability, Self-Refuting, Putnam, Kuhn.

\title{
REFERÊNCIAS
}

BURNYEAT, M. F. Protagoras and self-refutation in later Greek philosophy. The Philosophical Review, v. 85, n. 1, p. 44-69, 1976a.

. Protagoras and self-refutation in Plato's Theaetetus. The Philosophical Review, v. 85, n. 2, p. 172-195, 1976 b.

DOPPELT, G. Kuhn's epistemological relativism: an interpretation and defense. Inquiry, v. 21, p. 33-86, 1978.

FEYERABEND, P. Putnam on incommensurability. British Journal for the Philosophy of Science, v. 38, n. 1, p. 75-81, 1987.

GUITARRARI, R. Incomensurabilidade e racionalidade cientifica em Thomas Kuhn: uma análise do relativismo epistemológico. 2004. 247f. Tese (Doutorado em Filosofia) Faculdade de Filosofia, Ciências e Letras, Universidade de São Paulo, São Paulo, 2004.

. ; PLASTINO, C. E. Kuhn e as dimensóes da incomensurabilidade. Ideação, v. 1, n. 29, p. 31-62, 2014.

HOYNINGEN-HUENE, P. Reconstructing scientific revolutions: Thomas Kuhn's philosophy of science. Chicago; Londres: Chicago University Press, 1993.

KUHN, T. S. The structure of scientific revolutions. 2. ed. Chicago: Chicago University Press, 1970.

Second thoughts on paradigms. In: KUHN, T. S. The essential tension. Chicago: University of Chicago Press, 1977a. p. 293-319.

. Objectivity, value judgment, and theory choice. In: KUHN, T. S. The essential tension. Chicago: University of Chicago Press, 1977b. p. 320-339. 
. Commensurability, comparability, communicability. In: KUHN, T. S. The road since Structure. Chicago; Londres: The University of Chicago Press, 2000a. p. 32-57.

. The road since Structure. In: KUHN, T. S. The road since Structure. Chicago; Londres: The University of Chicago Press, 2000b. p. 90-104.

. The trouble with the historical philosophy of science. In: KUHN, T. S. The road since Structure. Chicago; Londres: The University of Chicago Press, 2000c. p. 105-120.

. Reflections on my critics. The road since Structure. Chicago; Londres: The University of Chicago Press, 2000d. p. 123-175.

LAKATOS, I. Falsification and the methodology of scientific research programmes. In: . ; MUSGRAVE, A. (Ed.). Criticism and the growth of knowledge. Cambridge: Cambridge University Press, 1970. p. 91-196.

MEILAND, J. W. Concepts of relative truth. The Monist, v. 60, n. 4, p. 568-582, 1977.

POPPER, K. R. Normal science and its dangers. In: LAKATOS, I.; MUSGRAVE, A. (Ed.). Criticism and the growth of knowledge. Cambridge: Cambridge University Press, 1970. p. 51-58.

PUTNAM, H. Reason, truth and history. Cambridge: Cambridge University Press, 1981.

. A defense of internal realism. In: . Realism with a human face. Massachusetts: Harvard University Press. 1990. p. 30-42.

. Renewing philosophy. Massachusetts: Harvard University Press, 1992.

. Pragmatism: an open question. Cambridge: Blackwell, 1995.

The collapse of the fact/value dichotomy and other essays. Cambridge: Harvard University Press, 2002.

RORTY, R. Solidarity or objectivity. In: Objectivity, relativism, truth. Philosophical papers. Cambridge: Cambridge University Press, 1991. V. 1. p. 21-34.

Recebido em 05/11/2015

Aceito em 07/12/2015 
GUITARRARI, R. 